\title{
Lissencephaly with cerebellar hypoplasia type C
}

INSERM

\section{Source}

INSERM. (1999). Orphanet: an online rare disease and orphan drug data base.

Lissencephaly with cerebellar hypoplasia type C. ORPHA:100013

Lissencephaly with cerebellar hypoplasia type C (LCHC) is a severe form of lissencephaly with cerebellar hypoplasia characterized by severe microcephaly, cleft palate, and severe cerebellar and brainstem hypoplasia leading to neonatal death. 